\title{
Nudging by shaming, shaming by nudging
}

\section{Nir Eyal ${ }^{*}$}

Correspondence to: Nir Eyal, Email: nir_eyal@hms.harvard.edu Copyright: ( 2014 by Kerman University of Medical Sciences

Citation: Eyal N. Nudging by shaming, shaming by nudging. Int J Health Policy Manag 2014; 3: 53-56. doi: 10.15171/ijhpm.2014.68

Received: 10 July 2014, Accepted: 24 July 2014, ePublished: 25 July 2014

\section{Nudging}

In both developing and developed countries, health ministries closely examine use of so-called nudges to promote population health and welfare. Cass Sunstein and Richard Thaler, who developed the concept, define a nudge as "any aspect of the choice architecture that alters people's behavior in a predictable way without forbidding any options or significantly changing their economic incentives. To count as a nudge, the intervention must be easy and cheap to avoid. Nudges are not mandates" (1). Two examples may illustrate this notion. Placing healthier food items at the cafeteria entrance and at eye level so that clients make healthier food choices is a nudge, according to Sunstein and Thaler. So are opt-out arrangements for cadaveric organ donation, so that more organs would be volunteered.

Nudges affect choice using neither rational persuasion nor restrictive means like mandates and substantial fines. Any pressure they apply is soft (2). In the cafeteria food choice example, the only 'cost' to customers who insist on unhealthy food choice is having to take a few steps to the other end of the cafeteria, where unhealthy food items are found. Nor do any nudges that Sunstein and Thaler would support include lies, deceit, subliminal advertising, or other powerful manipulation. Strong material incentives are also ruled out. The hope is that although the pressure that nudges exert is soft, nudges could affect choice considerably and improve health and welfare a lot. For instance, predictably, many customers will choose food placed at the entrance and at their eye level. Sunstein and Thaler explain that nudges are able to do so by exploiting our merely bounded rationality, as delineated by behavioral psychology in recent decades. Nudges allegedly make us healthier or happier without jeopardizing our freedom of choice.

It is an interesting philosophical question whether, so understood, nudges are possible at all. If so many of us predictably pick healthy food when it is placed in front of us, does not that mean or indicate that we are somehow forced to choose it, or are subtly but irresistibly manipulated? How can something tend so reliably to elicit a determinate choice without having forced that choice? Elsewhere I plan to explore how nudges may have this 'magical' effect. Our focus here is one account. It explains that while in nudges, nothing is objectively forcing the healthy choice, subjectively a strong desire issues or the nudge undercuts rational calculations, culminating in widespread response. In the cafeteria example, exceeding laziness or hyperbolic discounting makes most of us disproportionately averse to taking a few steps to the back of the cafeteria, or our appetite concentrates only around what we see first and blocks appetite for alternatives. This is not a rational response on our parts but the result is that we pick the first item we see.

This editorial does not question or defend this understanding of some nudges' mechanism of action. Instead it advances two hypotheses regarding the connection between nudging so characterized and shame, understood broadly to include embarrassment, stigma effects, and any compunction in general. One hypothesis I advance is that shame can serve in nudging. Another hypothesis is more critical. It states that nudging can instigate shame, which more restrictive measures to improve health would not.

These two hypotheses bear on the possibility and on the advisability of using nudges to promote personal and population health. They also bear on the cogency of the so-called least restrictive alternative principle in public health policy.

\section{Nudging by shaming}

One hypothesis is that shaming can be used for nudging as characterized above because shame can affect our choices a lot while objectively limiting our freedom of choice only little. The high impact of smoke-free legislation may rely in part on nudges that work this way. Zoning regulations create slight stigma, which may be objectively a trifle but which we dread. The same goes for the high impact of Directly Observed Therapy (DOT) for tuberculosis, which makes medical noncompliance awkward and embarrassing-again an objective trifle that we dread. Finally, whether New York City's potential ban on the sale of extra-large sugary drinks in movie theaters and other venues will work or founder will depend in part on whether enough residents will feel too embarrassed to order multiple soda cups and refills. Let me elaborate on each of these cases.

\section{Smoke-free regulation}

Around the turn of the millennium, countries, towns and workplaces the world over introduced restrictions on the geographical zones where smoking is allowed. These restrictions seem to have had a remarkable effect on smoking rates (3-7).

This public health triumph is worth explaining. For decades, public health anti-smoking campaigns met with little success. How did restrictions that make smoking only slightly less convenient (e.g. by forcing smokers to step outside certain 
buildings to smoke, or perhaps to stand a few steps away) have had such large effect on smoking prevalence? Many accounts can be given for this development. We shall focus on one account: that the process was mediated through subtle stigma. Being 'banished' for a few minutes from a building, to stand outside in a 'no-man's land', steps away, stresses us more than it objectively 'should', by instigating significant shame. Zoning laws impose no physical pain, no major burden and no fine (unlike e.g. negative subsidies for cigarettes). Any stigma they create is 'lite' (unlike refusal to hire smokers, which may count as severe stigma). Normally they involve no utter humiliation and dehumanization or a level of shame that threatens personal integrity. And yet, social animals are cued to react strongly to any signals of banishment. So the specter of even minor stigma prompts many smokers to smoke less or to quit. While additional mechanisms certainly explain the vast effect of smoke-free legislation (obviously secondhand smoking decreases when more smoking takes place outside shared spaces), the stigma and shame just delineated may form part of the reason. If so, smoke-free regulation is arguably an instance of successful nudging for public health.

\section{Directly observed therapy}

In DOT, a standardized treatment regimen, typically to cure tuberculosis (TB), is being directly observed by a healthcare worker or community health worker. This curative strategy is recommended by the World Health Organization (WHO) as the most effective way to stop the spread of $\mathrm{TB}$ in communities with a high incidence $(8,9)$. Short course DOT for $\mathrm{TB}$ is among the most cost-effective medical interventions in existence (10).

DOT does not include mandates to ingest one's pills or formal sanctions for non-compliers. In fact, WHO emphasizes that treatment observers must remain 'acceptable to the patient' and that the entire approach must remain 'patient centered' (9). What makes it the case, then, that mere watching of pill ingestion has such strong effect on whether patients will take their pills? Since observing is unaccompanied by the threat of penalty, how can it wield so much influence? The explanation is not simply that observers remind patients to do something that fundamentally these patients are committed to doing. Even in comparison to a far more intense regimen of text message reminders to ingest one's pills (coupled with some awkward human contact: a phone call in the event of recurring noncompliance), the evidence does not show that short course DOT is any the less effective (11).

Part of the reason for DOT's high effectiveness may be that the live presence of another person makes nonadherence highly embarrassing. That other person may lack the institutional power to force patients to take their pills. But it would usually be too embarrassing for patients-too socially awkward-to send her away with no results. Patients have the freedom to do so, but a vast majority chooses not to disappoint the observer and takes their pills. Objectively, sheer embarrassment is not profoundly bad for us, but social animals are disproportionately averse to it as well (12).

If this is a genuine part of DOT's mechanism of action, then it is arguably a nudge for health.
The super-size soda cup ban

On June 26, 2014, New York City lost its final appeal to ban the sale of $16 \mathrm{oz}$ or larger cups of high-calorie beverages in some public spaces. The proposed ban met with many objections $(13,14)$, one was that residents would remain free to buy several small cups or refills (15). That made the ban futile for opponents and not-overly-restrictive for proponents. In that respect, the success or failure of the ban, had it been implemented, would have depended on that of a shame-based nudge. The ban might have worked if enough customers with weight problems turned out to feel too embarrassed to buy several cups for themselves, or to return for a refill. Objectively, customers would remain free to buy and consume a large quantity of sugary soda. But under the gaze of other customers and vendors, at least, many might choose not to exercise that freedom.

Whether or not this calculation pans out in reality (once other jurisdictions introduce similar bans) remains anybody's guess. My point is that the proposed ban's effectiveness will hinge in part on whether it associates certain choices, such as buying multiple cups for oneself, with minor shame (and on whether societies will tolerate policy that must induce slight shame if it is to succeed).

\section{Shaming by nudging}

Nudging can also relate to shame in a more problematic way. A pitfall in the use of nudges is their potential to instigate pointless and sometimes serious and alarming shame, as an unintended side effect. This potential can make the use of nudges wrong in some contexts and some variants. It also indicates a problem with the least restrictive alternative principle in public health ethics.

Let me explain. The said attraction of nudging is that it is relatively non-restrictive-nudges are not mandates. However, highly restrictive measures can have some advantages as such, but they give us what are perceived as 'good excuses'. Because measures tagged as less restrictive do not provide perceived good excuses, nudging can instigate shame and guilt feelings which more restrictive interventions for personal and public health would not.

To elaborate, we rarely hold people fully responsible for choices made under duress, for example, for choices forced by violent threats. Nor do we hold people responsible for choices made under conditions of deceit, irresistible manipulation, and so forth. Less restrictive measures-including most nudges-are perceived as non-exculpatory (or as far less exculpatory), even when these measures predictably affect our choices as much. When the choices thus prompted run counter to choosers' or to their social circles' deep moral, personal, and religious commitments, they might prompt broadly construed shame and social penalties.

This becomes a problem when nudges are used for health promotion but against patients' own fundamental commitments or those of their immediate community's. If a nudge preserves free choice, and succumbing to it is totally avoidable, there is a worry that patients would be held responsible by themselves and by their peers for healthy choices that nevertheless violate their basic values. Patients 
would feel painful compunction or encounter social sanctions from which more restrictive methods would have saved them. In that respect, even when nudges successfully promote patients' health, they may set up patients for perceived moral or religious failure, and for the serious shame or strong banishment that may ensue. This illustrates, yet again (16-18), that having less choice is sometimes better for us. It also questions the least restrictive alternative principle in public health ethics.

Consider the examples of accepting medical services from medical students, and of donation of cadaveric organs.

\section{Opt-out of reliance on doctors in training}

In university hospitals around the world, some services are performed by medical students. This is an essential part of their training, and a future public health need. However, depending on the exact level of supervision, trainees' success rates can be far lower than those of trained medical personnel. That difference can be dramatic, for example, in the case of certain surgeries (19).

How to allocate fairly and sensibly among patients the risks from doctors' training (19)? While no guidelines are currently being implemented uniformly on this matter, the de facto solution is often as follows. Students partake in care quite fully but when a patient or her relatives vehemently object, procedures are performed by trained staff not students.

If you will, this is an opt-out approach to reliance on clinicians in training, and a nudge. The default is such that most patients will predictably forego ensuring that only trained personnel attends to them (partly because many patients and their families are too embarrassed to insist), but all maintain their freedom to receive services from trained personnel, because all would get them if they insisted enough.

Is this nudge a good solution? What about a more restrictive mandate that stated that patients who wish to continue to be seen in an academic medical facility with all its advantages, including the constant monitoring, study, and improvement of practices and the available innovations, and to enjoy services from staff trained at some risk to previous patients, must accept the related risks as well? Services from doctors in training will be frequently offered at academic centers, always allocated impartially (say, by lottery). Patients who insist on refusing them will have to move elsewhere for treatment and perhaps pay steep fines. Would not such a mandate be fairer and preferable in our context?

One argument against an opt-out nudge and in favor of a more restrictive mandate revolves around shame. The current opt-out solution relies on the prediction that many patients and their relatives will forego optimal care, although they had the freedom to demand and receive it. This solution promotes population health at some unnecessary psychosocial risk. Imagine that something goes awry and an aging parent or a young child suffers permanent disability because of choices made by her surrogate decision makers. Feelings of shame or guilt might arise, and mutual accusations might run high. By contrast, a mandate that left relatives (and patients) no choice except to receive services from medical students would exculpate decision makers completely. In that respect, a mandate would have been preferable. While a full assessment of the nudge and the mandate remains beyond our scope, we can affirm that in one respect, a more restrictive intervention would as such have an edge over a less restrictive nudge.

A mainstay of standard public health ethics is the 'least restrictive alternative' principle (20-22). It states, roughly, that less restrictive and less intrusive interventions for public health should be preferred to more intrusive and restrictive ones, at least when the expected effects on health are similar. If restrictive mandates have an advantage over nudges, perhaps the least restrictive alternative principle should be reexamined (23).

\section{Opt-out for cadaveric organ donation}

Most Islamic scholars fully endorse organ donation, but a significant minority of (usually Indo-Asian) Muslim scholars, imams, and doctors continue to oppose organ donation, especially post mortem $(24,25)$. Thus, even if population health or even the correct interpretation of the Qur'an support transplantation and organ donation from the deceased, many individuals see cadaveric donation as a forbidden violation of the body. Many families would be morally disappointed with a relative's permission to use his or her body parts after her death.

Sunstein and Thaler discuss opt-out policies for organ donation. Their optimism about the effects of these policies on the organ pool notwithstanding, they remain perfectly open to an alternate policy, of mandated choice (in which people must decide whether to become organ donors-or face criminal penalties). As they explain, an opt-out policy in which the default is set at donation would sometimes wind up harvesting organs from citizens who deeply oppose donation and who had left defaults in place only because they are averse to making choices $(1,18)$. One interpretation of their concern focuses on the shame that such a default arrangement might impose on such donors and their families.

Another way around this pitfall is to restrict use of nudging only to areas where the patient's own fundamental values agree with those of the intervention. So for example for those patients who are (far) more committed to maintaining the integrity of their bodies post mortem than to improving others' health, opt-out nudging would not be used. Interestingly, that's also an aspect of Sunstein and Thaler's approach, since for them (for quite a different reason), nudges must make people's lives go better 'as judged by their own preferences, not those of some bureaucrat' (1).

I do not mean to suggest here that concerns about shame are decisive against the use of nudges for increasing the organ pool, just that they, can count somewhat against it. A solution of mandated (cadaveric) organ donation (26) would have the advantage of exculpating patients from accusations of a perceived choice to violate religious mores. But it has other drawbacks (27).

Conclusion: nudges, shame, and the least restrictive alternative principle

Nudging is an important addition to the armamentarium of measures to promote personal and public health. Its 
connection to shame, stigma, and embarrassment is complex. Shame enables some nudges and makes others problematic. This connection merits further investigation. In addition, the least restrictive alternative principle in public health is not quite accurate. Interventions for health that are more restrictive are sometimes preferable as such.

\section{Acknowledgements}

The author is grateful to Emma Tieffenbach, Leah Price, Julien Deonna and Alexandre Dayer for their helpful comments.

Ethical issues

Not applicable.

\section{Competing interests}

Author declares that he has no competing interests.

Author's contribution

$\mathrm{NE}$ is the single author of the manuscript.

\section{References}

1. Sunstein $\mathrm{CR}$, Thaler $\mathrm{RH}$. Nudge: Improving Decisions About Health, Wealth, and Happiness. 1st edition. New Haven, CT: Yale University Press; 2008. doi: 10.1007/s10602-008-9056-2

2. Saghai $Y$. Salvaging the concept of nudge. J Med Ethics 2013; 39: 497-8. doi: 10.1136/medethics-2012-100727

3. Naiman $A B$, Glazier $\mathrm{RH}$, Moineddin $\mathrm{R}$. Is there an impact of public smoking bans on self-reported smoking status and exposure to secondhand smoke? BMC Public Health 2011; 11: 146. doi: 10.1186/1471-2458-11-146

4. Haw SJ, Gruer L. Changes in exposure of adult non-smokers to secondhand smoke after implementation of smoke-free legislation in Scotland: national cross sectional survey. BMJ 2007; 335: 549. doi: 10.1136/bmj.39315.670208.47

5. Sims M, Mindell JS, Jarvis MJ, Feyerabend C, Wardle H, Gilmore A. Did smokefree legislation in England reduce exposure to secondhand smoke among nonsmoking adults? Cotinine analysis from the Health Survey for England. Environ Health Perspect 2012; 120: 425-30. doi: 10.1289/ehp.1103680

6. Jimenez-Ruiz CA, Miranda JA, Hurt RD, Pinedo AR, Reina SS, Valero FC. Study of the impact of laws regulating tobacco consumption on the prevalence of passive smoking in Spain. Eur J Public Health 2008; 18: 622-5. doi: 10.1093/eurpub/ckn066

7. Callinan JE, Clarke A, Doherty K, Kelleher C. Legislative smoking bans for reducing secondhand smoke exposure, smoking prevalence and tobacco consumption. Cochrane Database Syst Rev 2010; 4: CD005992. doi: 10.1002/14651858.CD005992. pub2

8. World Health Organization (WHO). Tuberculosis (TB): Pursue high-quality DOTS expansion and enhancement. Element 3: Standardized treatment, with supervision and patient support. Geneva: WHO; 2014. [cited 2014 July 7]; Available from: http:// www.who.int/tb/dots/treatment/en/

9. World Health Organization (WHO). Treatment of tuberculosis: guidelines. 4th ed. Geneva: WHO; 2010.
10. Jamison DT. Disease Control Priorities in Developing Countries (DCP2). Washington DC: World Bank and Oxford University Press; 2006.

11. Nglazi MD, Bekker LG, Wood R, Hussey GD, Wiysonge CS. Mobile phone text messaging for promoting adherence to antituberculosis treatment: a systematic review. BMC Infect Dis 2013; 13: 566. doi: 10.1186/1471-2334-13-566

12. Eyal N. Motivating prevention: from carrots and sticks to "carrots" and "sticks". Virtual Mentor 2008; 10: 756-62. doi: 10.1001/ virtualmentor.2008.10.11.oped1-0811

13. Resnik D. Paternalistic Food and Beverage Policies. Public Health Ethics 2014; 7: 170-7. doi: 10.1093/phe/phu014

14. Young L. Court Rejects New York City's Portion Cap for Sugary Drinks. Huffington Post [serial on the Internet]. 2014; Available from: http://www.huffingtonpost.com/dr-lisa-young/court-rejectsnew-york-ci_b_5535621.html?utm_hp_ref=healthy-living

15. Chumley CK. New York City supersize soda ban a no-go, says state's highest court. The Washington Times. June 26, 2014; Available from: http://www.washingtontimes.com/news/2014/ jun/26/new-york-city-supersize-soda-ban-no-go-says-states/

16. Dworkin $\mathrm{G}$. Is more choice better than less? Midwest studies in Philosophy 1982; 7: 47-61.

17. Schneider CE. The practice of autonomy: patients, doctors, and medical decisions. New York: Oxford University Press; 1998.

18. Sunstein CR. Choosing not to choose. Behavioral Economics, Law, and Health Policy [video]. Harvard Law School, May 2, 2014. Available from: http://petrieflom.law.harvard.edu/events/ details/2014-annual-conference

19. Gawande A. The Learning Curve [internet]. The New Yorker. 2002 January 28. Available from: http://www.newyorker.com/ magazine/2002/01/28/the-learning-curve

20. Nuffield Council on Bioethics. Public health: Ethical issues. Cambridge: Cambridge University Press; 2007.

21. Kass N. An ethics framework for public health. Am J Public Health 2001; 91: 1776-82.

22. Gostin LO. Public health law: power, duty, restraint. Rev. and expanded. 2nd ed. Berkeley: University of California Press; 2008.

23. Saghai $Y$. Public health nudges and the principle of the least restrictive alternative. Behavioral Economics, Law, and Health Policy [video]. Harvard Law School, May 2, 2014. Available from: http://petrieflom.law.harvard.edu/events/details/2014-annualconference

24. Oliver M, Woywodt A, Ahmed A, Saif I. Organ donation, transplantation and religion. Nephrol Dial Transplant 2011; 26: 437-44. doi: 10.1093/ndt/gfq628

25. Ghaly M. Religio-ethical discussions on organ donation among Muslims in Europe: an example of transnational Islamic bioethics. Med Health Care Philos 2012; 15: 207-20. doi: 10.1007/s11019011-9352-x

26. Fabre C. Whose body is it anyway? Justice and the integrity of the person. Oxford: Oxford University Press; 2008.

27. Eyal N. Is the Body Special? Review article of Cécile Fabre, Whose Body is it Anyway? Utilitas 2009; 21: 233-45. doi: 10.1017/S0953820809003513 